\title{
Saponin in Poultry and Monogastric Animals: A Review
}

\author{
Sandeep K. Chaudhary ${ }^{1}$, Jaydip J. Rokade ${ }^{2 *}$, Ganesh N. Aderao ${ }^{1}$, Akansha Singh ${ }^{1}$, \\ M. Gopi ${ }^{2}$, Alok Mishra ${ }^{1}$ and Kanti Raje ${ }^{1}$ \\ ${ }^{1}$ ICAR-Indian Veterinary Research Institute, ${ }^{2}$ ICAR-Central Avian Research Institute, \\ Izatnagar, Bareilly, U.P.-243122, India \\ *Corresponding author
}

\section{A B S T R A C T}

\begin{tabular}{|l|}
\hline Key w or d s \\
Saponin, Poultry, \\
Immunity, Anti- \\
oxidant, Fertility, \\
Hatchability. \\
\hline Article Info \\
\hline $\begin{array}{l}\text { Accepted: } \\
\text { 24 June } 2018 \\
\text { Available Online: } \\
\text { 10 July } 2018\end{array}$ \\
\hline
\end{tabular}

Due to awareness of consumers towards clean and safe meat availability, plant secondary metabolites (PSMs) such as essential oils, organic acids, saponins and flavonoids etc. are rapidly gaining attention since last few decades. PSMs are the secondary compounds that are produced by plants and they don't have primary role as nutrients. These can be the effective alternative to antibiotics because of their promising effects on overall performance of poultry and monogastric animals. Saponins are high molecular weight glycosides which are able to form foam in aqueous solution. They are credited with several pharmacological and biological activities like hypocholesterolaemic, anti-carcinogenic, anti-microbial, anti-inflammatory, anti-oxidant and immunomodulatory effects on both poultry and animals. Saponins can be obtained from various parts of plants such as seed, stem, root, pericarp, shell and bark. Optimum level of saponin is being used as feed supplement in poultry and monogastric animal's nutrition and has shown many beneficial effects. In the present review an attempt was made to summarize these promising effects of saponin in poultry and monogastric animal's nutrition.

\section{Introduction}

Phytobiotics or phytogenic feed additives (PFAs) in poultry nutrition had shown many promising effects on overall production as well as welfare of the birds. Feed constitutes major production cost for these enterprises. The shortage of quality feed as well as rapid growth rate of poultry industry had made poultry enterprise more challengeable.

The phytogenic feed additives mainly comprise of organic acids, essential oils, saponins and flavonoids etc. and inorganic substances like antibiotics, growth promoters, etc. But there is increasing public concerns towards presence of chemical residues in poultry products and microbial resistance to antibiotics. Therefore, use of phytogenic feed additives against antibiotics as performance enhancer is becoming very popular practice now days (Wallace et al., 2002). Thus, the present review had made an attempt compile the information's on one of the important PSMs, saponin in poultry production. 


\section{Saponin}

Saponins are diverse group of high molecular weight plant secondary metabolites (PSMs), containing either a tetracyclic steroidal or a pentacyclic triterpenoid aglycone and one or more sugar chains. The name is presumed from the Latin word sapo (soap) reflecting their wide spread ability to form stable soaplike foams in aqueous solutions (Vincken et al., 2007).

\section{Chemistry of saponins}

Sugar moieties (pentoses, hexoses or uronic acid) of saponin is glycosidically linked to a hydrophobic aglycone (sapogenin) which may be either triterpenoid or steroid in nature (Francis et al., 2002). Triperpenes are the most widely, naturally occurring saponins. The skeleton of triterpenoid and steroid saponins are oleanane and spirostane or furostane, respectively (Sparg et al., 2004; Siegler, 1998). The biological property of saponins varies according to the ring structure of aglycone moieties and number of sugars attached to it.

\section{Effects of saponins}

\section{Effect on feed intake, growth and litter quality}

Optimum dietary level of saponin from different sources, favored higher growth rate, better feed efficiency (Yejuman et al., 1998), as well as reduced the emission of noxious ammonia from excreta (Al-Bar et al., 1993) thereby improving the health and welfare of poultry and pigs (Anthony et al., 1994). Addition of Chlorophytum root @ 0.015\% in broilers has shown improvement in nitrogen utilization and profitability (Gaurav, 2015). Gaurav (2015) reported a higher growth rate in Camellia seed saponin supplemented (@ $600 \mathrm{mg} / \mathrm{kg}$ ) group. Miah et al., (2004) reported that diet containing $75 \mathrm{mg}$ saponin/kg had improved body weight gain at all stages of growth with better feed efficiency and performance index as well as improved carcass quality. Saponins increase the permeability of intestinal mucosal cells invitro, inhibit active mucosal transport and facilitate uptake of substances that are normally not absorbed (Johnson et al., 1986). In optimum levels, it would increase nutrient absorption from the intestine by increasing villi diameter by $40-50 \mathrm{~A}^{\circ}$ thereby making those permeable to large molecules like ferritin; this fact may be responsible for better growth rate (Seeman et al., 1973).

Ammonia, a bacterial breakdown product of uric acid is the most noxious gas in poultry houses. Poor management practices and wet litter are the predisposing factors, favoring the continual release of ammonia from the litter. Excessive levels of ammonia are detrimental for broiler health (Yeo and Kim, 1997). Yucca schidigera extract has been reported to reduce atmospheric ammonia in poultry farms by inhibiting urease enzyme activity (Ayasan $e t$ al., 2005). Chaudhary (2017) reported that supplementation of soapnut shell powder @ $150 \mathrm{ppm}$ had significantly reduced excreta moisture content, thus, helped in reducing pollution as well as improved welfare of broiler breeders.

\section{Effect on serum and meat cholesterol levels}

A number of studies had shown that saponins from different sources lowered serum cholesterol levels (Matsuura, 2001; Gaurav, 2015, Chaudhary, 2017). Saponin and bile acids interaction in the gut leads to formation of large mixed micelles which promotes increased cholesterol excretion (Oakenfull, 1986) and finally results in reduction of serum cholesterol level. It has been found that the ethanolic extract of de-fatted fenugreek seeds inhibits taurocholate and deoxycholate absorption in-vitro, in a dose-dependent manner in everted intestinal sacs (Stark and 
Madar, 1993). The hypocholesterolemic activity of saponins is also due to delaying of intestinal absorption of dietary fat by inhibiting pancreatic lipase activity (Han et al., 2000). Saponins are also reported to reduce the harmful LDL-cholesterol selectively in the serum of rats, gerbils as well as in poultry (Matsuura, 2001; Gaurav, 2015; Chaudhary, 2017).

Gaurav (2015) and Chaudhary (2017) reported that serum total cholesterol level was significantly decreased and the HDLcholesterol was significantly increased following supplementation of saponin rich feed additives. Researchers reported that saponins from different sources had lowered serum cholesterol level in broiler chickens (Matsuura, 2001; Afrose et al., 2010; Owolabi et al., 2010).

Age of the broilers and presence of saponin in feed or both, influences the total cholesterol content in breast meat. Ponte et al., (2004) in their study found that Alfalafa saponin lowered the total cholesterol in the meat without affecting the in-vivo biosynthesis of cholesterol.

\section{Effect on haemato-biochemical parameters}

Gupta et al., (2005); Gaurav (2015) and Chaudhary (2017) did not find any significant change in haemato-biochemical parameters ( Hb, PCV, Glucose, creatinine, total protein, albumin, globulin, A: $\mathrm{G}$ ratio, calcium, inorganic-phosphorus, SGOT, SGPT and ALP) in rats, chickens and broiler breeders following supplementation with saponin from different sources. Kaya et al., (2004) reported that dietary supplementation of Yucca powder @ 100 ppm to quails did not affected serum total protein concentration but albumin level was decreased.

\section{Effect on antioxidant activity}

Antioxidants are the compounds which inhibits the oxidation of other molecules. Oxidation is a chemical reaction produces free radicals that damages the cells and manifest as adverse biological effects. Superoxide dismutase (SOD), glutathione peroxidase (GPx) and catalase (CAT) are the main antioxidant enzymes in the body, contributing to the antioxidant activity. Shi et al., (2014) reported that activity of these antioxidant enzymes was increased significantly following supplementation of alfalfa saponin extract @ $15 \mathrm{~g} / \mathrm{kg}$ in weaned piglets. Malondialdehyde (MDA) is one of the most frequently used indicators of lipid peroxidation.

Increased MDA can be interpreted as cellular membrane damage (Niedernhofer et al., 2003). MDA content in the serum, liver, spleen and muscle was decreased following alfalfa saponin extract supplementation in weaned piglets (Shi et al., 2014).

Group-B soyasaponins from legumes (kidney beans, peanuts, chickpeas, clover, and Japanese bush clover etc.), contains an antioxidant moiety at C23, DDMP (2,3dihydro-2,5-dihydroxy-6-methyl-4H-pyran-4one) which allows saponins to scavenge superoxide's by forming hydroperoxide intermediates, and thus preventing biomolecular damage by free radicals ( $\mathrm{Hu}$ et al., 2002).

The administration of saponin from Solanum anguivi fruit significantly increased both CAT and SOD activities in heart, whereas, concentration of MDA was decreased (Elekofehinti et al., 2012). Diosgenin (a steroidal sponin of Dioscorea spp.) supplementation $(0.5 \%)$ caused a $27 \%$ and $13 \%$ increase in GPx and CAT activities in erythrocytes of rats (Son et al., 2007). 


\section{Effect on immune system}

Saponins are capable of stimulating immune system and thereby enhancing resistance to the diseases (Cheeke, 2001). Saponins can stimulate secretion of cytokines and trigger innate immunity (Song and Hu, 2009), as well as enhance humoral and cellular immune responses (Palatnik et al., 2004). Significant immune-stimulation and protection to diseased are achieved by immunization of chickens with immune-stimulating complexes contained purified saponins (Berezin et al., 2010). Zhai et al., (2014) reported that administration of saponins isolated from ginseng stems and leaves through drinking water of chickens significantly enhanced the immune responses to vaccination against Newcastle disease, avian influenza and infectious bursal disease. Sahoo et al., (2015) reported that antibody titre against Newcastle disease virus in broiler chicks on $7^{\text {th }}$ and $14^{\text {th }}$ day post-vaccination was significantly higher in the Yucca schidigera extract group. Supplementation of Yucca up to 100 or 150 $\mathrm{mg} / \mathrm{kg}$ diet improved immunity in layers (Alagawany et al., 2016). Chaudhary (2017) reported that soapnut shell powder saponin@ 75 and $150 \mathrm{ppm}$ had significantly improved both cell mediated and humoral immune response in broiler breeders.

\section{Effect on egg production and egg quality}

Yucca supplementation up to $100 \mathrm{mg} / \mathrm{kg}$ in diet is effective in improving egg production, egg mass and shell thickness in laying hens (Alagawany et al., 2016). Ayasan et al., (2005); Gurbuz et al., (2011) and Alagawany et al., (2016) observed that Yucca supplementation to layer's diet had no effect on egg weight, shape index and shell weight compared to non-supplemented groups. Guclu (2003) and Kutlu et al., (2001) reported that Yucca extract supplementation to the layers did not affect egg production, albumin and yolk index, shape index, Haugh unit and shell thickness but reduced egg's specific gravity and number of cracked eggs. Egg yolk cholesterol and triglycerides were significantly reduced by dietary Karaya saponin supplementation (Afrose et al., 2010). Chaudhary (2017) reported that broiler breeders supplemented with graded level of soapnut shell powder saponin did not manifest any significant difference in quality of egg lay.

\section{Effect on semen quality and sex hormones}

Miah et al., 2004 reported that supplementation of saponin resulted in an increased testis size in male broiler birds s. An increase in seminiferous tubule diameter in cockerels receiving a diet containing 100 $\mathrm{mg} / \mathrm{kg}$ saponin was reported by Hong et al., (1976). SFTT (Saponin rich fraction of Tribulus terrestris) had a beneficial effect on male reproductive functions in rats. It altered reproductive functions in males and improved the quality of spermatozoa. SFTT (Saponin rich fraction of Tribulus terrestris) treated rats had significantly higher sperm concentration compared to control (Hemalatha and Hari, 2015).

Rats fed with 5\% Panax ginseng have shown significant increase in blood testosterone levels (Fahim et al., 1982). Ginsenosides are triterpenoid saponins found in Panax ginseng that structurally resemble the steroid hormones. Ginsenoside $\operatorname{Rg} 1$, the major active constituent in Panax ginseng, is responsible for the increased serum testosterone levels and improvement in the copulatory behavior (Wang et al., 2010). Ginsenoside Rb1, a key ginsenoside found in American ginseng, is found to increase the secretion of $\mathrm{LH}$ by acting directly on the anterior pituitary gland (Tsai et al., 2003). Oyeyemi et al., (2015) reported an increased sperm motility and count with increasing dose of saponin from Vernonia amygdalina treatment to male wistar 
rats resulted in an increased fertilizing capacity of the spermatozoa. Balazi et al., (2013) reported that Yucca schidigera administration increased the spermatozoa concentration and motility of rabbit buck. Chaudhary (2017) reported that soapnut shell powder supplementation to broiler breeders had significantly improved the semen quality as well as serum and seminal plasma testosterone levels.

\section{Effect on fertility, hatchability and embryonic mortality}

Fertility, hatchability and embryo mortality are the major parameters of reproductive performance of a breeding flock. Yucca schidigera supplementation @ 120 ppm in diet did not affect hatchability of total eggs set, hatchability of fertile eggs set and fertile egg percent in quails (Ayasan, 2013). Enaiat et al., (2011) found that cocks supplemented with Yucca schidigera and Yucca schidigera in combination with aluminum chloride had recorded significantly higher fertility percent than control. Chaudhary (2017) reported that supplementation of soapnut shell powder saponin@75 ppm in diet to broiler breeders had significantly improved fertility, hatchability of total eggs set and hatchability of fertile eggs set as well as decreased total embryonic mortality.

It is concluded from above information that saponins reduces total cholesterol and LDLcholesterol levels in serum and meat. Also it improves semen quality as well as testosterone level in serum and seminal plasma of both poultry and mono-gastric animals vis a vis improves fertility and hatchability of eggs.

Saponins helps in overall improvement in production, immunity, litter quality, gut health, meat quality and welfare of poultry as well as monogastric animals without affecting cost economics. So, it can be used as an alternative to antibiotics for production of clean and green meat which ultimately helps us to achieve one health concept.

\section{References}

Afrose, S., Hossain, M.S. and Tsujii, H. 2010. Effect of dietary Karaya saponin on serum and egg yolk cholesterol in laying hens. British Poultry Science. 51: 797-804.

Alagawany, M., El-Hack, M.E.A. and ElKhol, M.S. 2016. Productive performance, egg quality, blood constituents, immune functions, and antioxidant parameters in laying hens fed diets with different levels of Yucca schidigera extract. Environmental Science and Pollution Research. 23: 6774-6782.

Al-Bar, A., Ismail, A., Cheehe, P.R. and Nakaue, H. 1993. Effect of dietary Yucca scidegera extract (Deodorage) on environment ammonia and growth performance of chicken and rabbits. Proceeding of Western Section of American Society of Animal Science. 44: 106.

Anthony, N.B., Balog, J.M., Staudinger, F.B., Wall, C.W., Walker, R.D. and Huff, W.E. 1994. Effects of a urease inhibitor and ceiling fans on ascites in broilers. Environmental variability and incidence of ascites. Poultry Science. 73: 801-809.

Ayasan, T. 2013. Effects of dietary Yucca schidigera on hatchability of Japanese quails. Indian Journal of Animal Sciences. 83(6): 641-644.

Ayasan, T., Yurtseven, S., Baylan, M. and Canogullari, S. 2005. The effects of dietary yucca schidigera on egg yield parameters and egg shell quality of laying Japanese quails (Coturnix coturnix japonica). International 
journal of poultry science. 4(3): 159162

Balazi, A., Foldesiova, M., Chrastinova, Sirotkin, A.V. and Chrenek, P. 2013. Effect of the herbal additive Yucca on rabbit spermatozoa characteristics. Journal of Microbiology and Biotechnology and Food Sciences. 2: 1829-1837.

Berezin, V.E., Bogoyavlenskyi, A.P., Khudiakova, S.S., Alexuk, P.G., Omirtaeva, E.S. and Zaitceva, I.A. 2010. Immunostimulatory complexes containing Eimeria tenella antigens and low toxicity plant saponins induce antibody response and provide protection from challenge in broiler chickens. Veterinary Parasitology. 167: $28-35$.

Chaudhary, S.K. 2017. Assessment of the performance of broiler breeders fed diet containing soapnut (Sapindus mukorossi) shell powder. M.V.Sc. Thesis, Deemed University, Indian Veterinary Research Institute, Izatnagar pp. 78-80.

Cheeke, P.R. 2001. Actual and potential applications of Yucca schidigera and Quillaja saponaria saponins in human and animal nutrition. Recent Advances in Animal Nutrition in Australia. 13: 115-126.

Elekofehinti, O.O., Adanlawo, I.G., Fakoya, A., Saliu, J.A. and Sodehinde, S.A. 2012. Effect of saponin from Solanum anguivi Lam. fruit on heart and kidney superoxide dismutase, catalase and malondialdehyde in rat. Current Research Journal of Biological Science. 4: 530-533.

Enaiat, A.M.M.E., Abou-Eitta, E.M., Salem, A. and Al-Kotait, A.H.A. 2009. Effect of Yucca schidigera extract and aluminum chloride on pen's atmospheric ammonia, productive, reproductive and physiology performance of silver montazah cocks. Egyptian Poultry Science. 29(1): 337356.

Fahim, M.S., Fahim, Z., Harman, J.M., Clevenger, T.E., Mullins, W. and Hafez, E.S. 1982. Effect of Panax ginseng on testosterone level and prostate in male rats. Archives of Andrology. 8: 261-263.

Francis, G., Kerem, Z., Makkar, H.P.S. and Becker, K. 2002. The biological action of saponins in animal systems: A review. British Journal of Nutrition. 88: 587-605.

Gaurav, A.K. 2015. Studies on supplementation of Chlorophytum root and Camellia seed as feed additives in broiler ration. M.V.Sc. Thesis, Deemed University, Indian Veterinary Research Institute, Izatnagar pp. 50-61.

Guclu, B.K. 2003. The effects of Yucca schidigera extract added to quail rations on egg production, egg quality and some blood parameters. Turkish Journal of Veterinary and Animal Sciences. 27: 567-574

Gupta, R.S., Chaudhary, R., Yadav, R.K., Verma, S.K. and Dobhal, M.P. 2005. Effect of Saponins of Albizia lebbeck (L.) Benth bark on the reproductive system of male albino rats. Journal of Ethnopharmacology. 96: 31-36.

Gurbuz, E., Balevi, T., Kurtoglu, V. and Oznurlu Y. 2011. Use of yeast cell walls and Yucca schidigera extract in layer hens' diets. Italian Journal of Animal Science. 10(2): 134-138.

Han, L.K., Xu, B.J., Kimura,Y., Zheng, Y.N. and Okuda, H. 2000. Platycodi radix affects lipid metabolism in mice with high fat diet induced obesity. Journal of Nutrition. 130: 2760-2764.

Hemalatha, S. and Hari, R. 2015. Fertility enhancing effect of saponin rich butanol extracts of Tribulus terrestris 
fruits in male albino rats. International Journal of Pharmaceutical and Clinical Research. 7(1): 36-43

Hong, B.J., Kim-Cl, U.H. and Rec, Y.C. 1976. Effect of feeding ginseng crude saponin extract on body weight gain and reproductive function in poultry. Korean Journal of Animal Science. 18: 355-361.

Hu, W.L., Liu, J.X., Wu, Y.M., Guo, Y.Q. and Ye, J.A. 2006. Effects of tea saponins on in-vitro ruminal fermentation and growth performance in growing Boer goat. Archives of Animal Nutrition. 60: 89-97.

Johnson, I.T., Gee, J.M., Price, K., Curl, C. and Fenwick, G.R. 1986. Influence of saponins on gut permeability and active nutrient transport in vitro. Journal of Nutrition. 116: 2270-2277.

Kaya, S., Erdogan Z. and Erdogan, S. 2004. Effect of different dietary levels of Yucca schidigera powder on the performance blood parameters and egg yolk cholesterol of laying quails. Proceedings of the 22nd World Poultry Congress, June 8-13, Istanbul, Turkey.

Kutlu, H.R., Gorgulu, M. and Unsal, I. 2001. Effects of dietary Yucca schidigera powder on performance and egg cholesterol content of laying hens. Journal of Applied Animal Research. 20(1): 49-56.

Matsuura, M. 2001. Saponins in garlic as modifiers of the risk of cardiovascular disease. Journal of Nutrition, 131: 1000S-1005S.

Miah, M.Y., Rahman, M.S., Islam, M.K. and Monir, M.M. 2004. Effects of Saponin and L-Carnitine on the Performance and Reproductive Fitness of Male Broiler. International Journal of Poultry Science. 3(8): 530- 533.

Niedernhofer, L.J., Daniels, J.S., Rouzer, C.A., Greene, R.E. and Marnett, L.J.
2003. Malondialdehyde a product of lipid peroxidation, is mutagenic in human cells. The Journal of Biological Chemistry. 278: 31426-31433.

Oakenfull, D. 1986. Aggregation of saponins and bile acids in aqueous solution. Australian Journal of Chemistry. 39: 1671-1683 Osbourn, A.E. 2003. Saponins in cereals. Phytochemistry. 63: 1-4.

Owolabi, O. A., James, D. B., Ibrahim, A. B., Folorunsho, O. F., Bwalla, I. and Akanta, F. 2010. Changes in lipid profile of aqueous and ethanolic extract of Blighia sapida in rats, Asian Journal of Medical Sciences. 2: 177180.

Oyeyemi, M.O., Soetan, K.O., and Akinpelu, O.B. 2015. Sperm characteristics and haemogram of male albino rats (wistar strain) treated with saponin extract from Vernonia amygdalina del. asteraeceae 110192. Journal of Cell and Animal Biology. 9(3): 26-30.

Palatnik de Sousa, C.B., Santos, W.R., Casas, C.P., Paraguai de Souza, E., Tinoco, L.W. and da Silva, B.P. 2004. Protective vaccination against murine visceral leishmaniasis using aldehydecontaining Quillaja saponaria sapogenins. Vaccine. 22: 2470- 2479.

Ponte, P.I.P., Mendes, I., Quaresma, M., Aguiar, M.N.M., Lemos, J.P.C., Ferreira, L.M.A., Soares, M.A.C., Alfaia, C.M., Prates, J.A.M. and Fontes, C.M.G. 2004. Cholesterol levels and sensory characteristics of meat from broilers consuming moderate to high levels of Alfalfa. Poultry Science. 83: 810-814.

Sahoo, S.P., Kaur, D., Sethi, A.P.S., Chandrahas, Saini, A.L. and Chandra, M. 2015. Effect of dietary supplementation of Yucca schidigera extract on the performance and litter quality of broilers in winter season. 
Animal Nutrition and Feed Technology. 16: 475-484.

Seeman, P., Cheng, D. and Iles, G.F. 1973. Structure of membrane holes in, osmotic and saponins hemolysis. Journal of Cell Biology. 56: 519-527.

Shi, Y.H., Wang, J., Guo, R., Wang, C.Z., Yan, X.B., Xu, B. and Zhang, D.Q. 2014. Effects of alfalfa saponin extract on growth performance and some antioxidant indices of weaned piglets. Livestock Science. 167: 257-262.

Siegler, D.S. 1998. Saponins and cardnolides in plant secondary metabolism. Kluwer Academic Publishers, Broton/Dordrecht/London. 427-455.

Son, I.S., Kim, J.H., Sohn, H.Y., Son, K.H., Kim, J. S. and Kwon, C.S. 2007. Antioxidative and hypolipidemic effects of diosgenin, a steroidal saponin of yam (Dioscorea spp.), on high-cholesterol fed rats. Bioscience, Biotechnology and Biochemistry. 71: 3063- 3071.

Song, X. and Hu, S. 2009. Adjuvant activities of saponins from traditional Chinese medicinal herbs. Vaccine. 27: 48834890.

Sparg, S.G., Light, M,E. and van Staden, J. 2004. Biological activities and distribution of plant saponins. Journal of Ethnopharmacology. 94: 219-243.

Stark, A. and Madar, Z. 1993. The effect of an ethanol extract derived from fenu greek (Trigonella foenum-graecum) on bile acid absorption and cholesterol level in rats. British Journal of Nutrition. 69: 277-287.

Tsai, S.C., Chiao, Y.C., Lu, C.C. and Wang,
P.S. 2003. Stimulation of the secretion of luteinizing hormone by ginsenoside- $\mathrm{Rb} 1$ in male rats. The Chinese Journal of Physiology 46:1-7.

Vincken, J.P., Heng, L., de Groot, A. and Gruppen, H. 2007. Saponins, classification and occurrence in the plant kingdom. Phytochemistry. 68: 275-297.

Wallace, R.J., McEwan, N.R., McIntosh, F.M., Teferedegne, B. and Newbold, C.J. 2002. Natural products as manipulators of rumen ferementation. Asian-Australasian Journal of Animal Sciences. 15: 1458-1468.

Wang, X., Chu, S., Qian, T., Chen, J. and Zhang, J. 2010. Ginsenoside Rg1 improves male copulatory behavior via nitric oxide/cyclic guanosine monophosphate pathway. The Journal of Sexual Medicine. 7: 743-50.

Yejuman, Y.H., Shiminghua, J., Niweiju, M.H., Yeja, M. and Shi, N.I. 1998. Effect of herbal origin bioactive substances on growth rate and some biochemical parameters in blood of broilers. Journal of Zhejiang University. 24: 405- 408.

Yeo, J. and Kim, K. 1997. Effect of feeding diets containing an antibiotic, a probiotic, or yucca extract on growth and intestinal urease activity in broiler chicks. Poultry Science 76:381-385.

Zhai, L., Wang, Y., Yu, J. and Hu, S. 2014. Enhanced immune responses of chickens to oral vaccination against infectious bursal disease by ginseng stem-leaf saponins. Poultry Science. 93: 2473-2481.

\section{How to cite this article:}

Sandeep K. Chaudhary, Jaydip J. Rokade, Ganesh N. Aderao, Akansha Singh, M. Gopi, Alok Mishra and Kanti Raje. 2018. Saponin in Poultry and Monogastric Animals: A Review Int.J.Curr.Microbiol.App.Sci. 7(07): 3218-3225. doi: https://doi.org/10.20546/ijcmas.2018.707.375 